\section{Learning lessons from NASA's failed science missions}

Sir - The probable failure of NASA's Mars Polar Lander, coming so soon after the loss of the Mars Climate Orbiter, will once again call into question the agency's policy of 'faster, better, cheaper' missions (Nature $402,565 ; 1999)$. There is a perception that faster and cheaper is only achieved by taking undue risk. The European Space Agency (ESA) is now changing the nature of its science programme to include faster and cheaper missions, so it is important to understand the pitfalls and benefits of the US experience. Using databases of past US space-science missions, I have assessed the impact of the changed philosophy on the NASA programme.

The number of space-science missions fell systematically from 40 in the eight-year period beginning in 1961 to just 11 in that up to 1992. A projection of the programme evolution made in 1992 would have predicted that, early in the twenty-first century, one space-science mission per decade would become the norm. Clearly, there was a need to reverse the trend: to make missions take place within a shorter schedule and cost less.

Since 1992, the trend has indeed been reversed and there have been 25 spacescience mission launches - double the rate in preceding years. But what has been the effect on the failure rate?

As a measure of reliability, I have considered the number of NASA missions for which a failure in the spacecraft brought science operations to a halt earlier than otherwise would have been the case. Such an early end to operations does not necessarily mean that the mission was a failureoften the spacecraft failure came after the prime objectives had been achieved. In the 1960s there was an early end to operations in at least $30 \%$ of the missions. Each mission usually involved new technology and at that time there were many lessons to be learned. In the 1970s and early 1980s, an early end to operations occurred in only about $10 \%$ of space-science missions. In the years immediately before 1993 , the rate was $18 \%$. Since 1992 it will be $24 \%$ if Mars Polar Lander is unsuccessful.

A second way of making a comparison is to identify the missions for which it is indisputable that prime objectives were not achieved. In the 1960s, problems occurred before prime objectives were achieved in only $5 \%$ of missions. From 1968 to the end of 1992, the failure rate was only $2 \%$ (one in 55 missions). For the seven years since 1992, the rate will be $24 \%$ if Mars Polar Lander is unsuccessful (six out of 25 missions). If there is a clear distinction between missions of the 'faster, better, cheaper' era and earlier ones, it is in the increase in the relative number of missions that fail to achieve their prime objectives. Causes of these recent failures include use of a relatively untried launcher, omissions and misinterpretations in the project implementation at several stages, and a failure to convert imperial units to metric.

Before making a final judgement, we should consider the benefits of the new philosophy. The dilemma is that space science carries a high risk, failures are well publicized, and it is less easy to make the same impact with successes. One conclusion is that the US programme has become broader since the change in philosophy. There has been more emphasis on technology demonstration during missions, rather than as a separate activity, and more emphasis on public outreach and education. Broadening the scope of the programme has only been possible because the mission frequency has increased.

For solar terrestrial physics, the emphasis has always been on relatively small spacecraft but in various combinations. Here, the change since 1992 is not dramatic except for a considerable reduction in mission gestation time. For astronomy, the change has been from major missions that one by one extended the wavelength range of observations to smaller missions, each with a more focused set of objectives, building on the observations of the earlier spacecraft. The SWIFT mission is a typical example of a faster, cheaper mission building on discoveries of earlier missions. For planetary science, there has been a major transition from relatively rare but comprehensively instrumented observatories to several much smaller missions with well-focused objectives and with technology demonstration an important ingredient.

To some extent, 'faster, better, cheaper' was a natural next step to follow the major observatory missions of the 1970s and 1980s. But the change in philosophy has not been introduced to the exclusion of the 'slower, expensive' missions: Chandra, SIM, NGST, TPF and Solar Probe all figure in the programme and are the equivalent of missions before 1992. There is no reason to conclude that the changed philosophy has led to a diminution of the science return. On the contrary, while major missions remain part of the programme (though at lower cost), there are now many additional missions, each with short gestation times. Those faster, cheaper missions provide opportunities and science return that was missing from the programme in the 1980s. Perhaps the individual missions may not be 'better' than those of the earlier programmes, but, for the programme overall, 'better' is a suitable description.
ESA has learned from its experience with Cluster to be wary of untried launchers. Fortunately, Europe moved away from mixing metric and imperial units several years ago. The other NASA failures give warnings on how far a 'faster, better, cheaper' approach can be pushed. An advantage that we have in Europe is that there are faster and cheaper programmes running in parallel with the ESA programme. These national missions have a smaller scope than ESA missions and so are implemented more quickly with smaller budgets. These, too, can provide valuable lessons on how far the quest for low cost can be taken. We need to make sure that there is good communication between the ESA and European national programmes, so that we all can learn.

Dave Hall

British National Space Centre, 151 Buckingham Palace Road, London SW1W 9SS, UK

\section{Online research archive will be free to all}

Sir - Lance Sultzbaugh criticizes the PubMed Central initiative for having done nothing to change the problems with typical schemes of online scientific publishing (Nature 402, 230; 1999). He says these schemes are difficult to navigate, reside behind cost barriers and conform to no archival standards. It is a little unfair to criticize PubMed Central for being difficult to navigate and lacking in standards before it even exists, but these are certainly valid concerns. It is ridiculous, however, to claim that PubMed Central does nothing to address the cost barriers to accessing scientific literature.

The key characteristic of PubMed Central is that all the research it will archive will be available in full to any individual, at no charge. This applies to research that enters via existing journals that choose to participate, and to research that uses a new peerreview route such as BioMed Central or the Community of Science's scheme.

The PubMed Central model retains a decentralized system of peer review, which is desirable in that no single body can control what gets published. On the other hand, it centralizes the infrastructure necessary to allow trustworthy long-term archiving, effective searching and reliable linking. And it does away with the barriers to access that have prevented the web from achieving its full potential for enhancing scientific communication.

When PubMed Central and BioMed Central are launched, scientists will finally have a viable alternative to traditional journals. Research made available through PubMed Central will be freely accessible, 
and yet will also be accepted as a credible, citable contribution to the literature. Surely this deserves to be applauded.

Matthew Cockerill

BioMed Central Ltd, 34-42 Cleveland Street, London W1P 6LE, UK

\section{How reliable is science information on the web?}

Sir - Until recently, the dissemination of scientific information has largely been regulated by publishers via peer review and by librarians through their purchases of journals. With the advent of the WorldWide Web, however, the publication of science has been democratized. Although this 'deregulation' will speed the flow of valuable information around the world, a negative side effect may be the increased exposure of students and the public to misleading or biased science, or to opinion masquerading as science. Here, we report on the overall reliability of websites that purvey scientific information.

Our results are sobering. Although the web is increasingly used as a source of scientific information, the quality of the information provided by many of the most easily accessed sites is poor. To gain an understanding of the quality of information on the web, we performed searches for the terms 'evolution' (EV), 'genetically modified organism' (GMO) and 'endangered species' (ES) using Northernlight.com, the search engine with the broadest reported coverage of the web ${ }^{1}$.

The first 500 websites retrieved for each topic were examined sequentially by two referees until each had independently reviewed approximately 60 sites containing information pertinent to the topic. These informative sites were scored as 'inaccurate' if they contained information that was factually incorrect, 'misleading' if they misinterpreted science or blatantly omitted facts supporting an opposing position, and 'unreferenced' if they presented information without any peer-reviewed references.

For EV, only $12 \%$ ( 59 of 500 ) of the websites examined were considered informative by both referees. For GMO and ES, 46\% (64 of 140) and 28\% (55 of 200) of sites, respectively, were considered informative. Of informative sites, the proportion that were judged inaccurate ranged from 10\% for GMO to 34\% for EV (Fig. 1). Likewise, the proportion of informative sites scored as misleading ranged from $20 \%$ for ES to $35 \%$ for EV. A much higher proportion of sites were unreferenced (more than $48 \%$ for each category), but the presence or absence of references does not necessarily correspond with the other scores.

Overall agreement values for the refer-

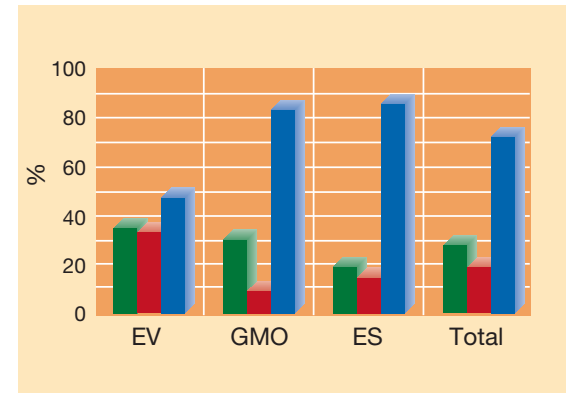

Figure 1 Percentage of informative websites reviewed for the search topics 'evolution' (EV), 'genetically modified organism' (GMO) and 'endangered species' (ES) that were misleading (green bars), inaccurate (red bars), and unreferenced (blue bars). Data are averaged across referees.

ees' scores for the categories of 'inaccurate' and 'misleading' were $87.8 \%$ for EV sites, $82.8 \%$ for GMO sites and $73.6 \%$ for ES sites. Because the presence or absence of peer-reviewed citations is not subjective, no agreement values were calculated for this category.

Our results indicate that science-related websites have serious liabilities. Many sites purporting to contain science are simply presentations of opinion or social commentary. And the presence of peer-reviewed citations, normally a sign of reliability, does not necessarily reflect the quality of the information presented. Nonetheless, we recognize the substantial advantages conferred by global access to the huge stores of information on the web, particularly for those who might otherwise have limited access to scientific resources.

One promising strategy for such users is the exploitation of recently established portals that provide links to sites that have been reviewed by scientists for accuracy, relevance and currency ${ }^{2-4}$. These portals, if widely used, also offer a means of establishing peer review as the guiding principle for evaluating science on the web ${ }^{5}$.

Eva S. Allen, John M. Burke, Mark E. Welch, Loren H. Rieseberg

Department of Biology, Indiana University, $1001 \mathrm{E}$. 3rd Street, Bloomington, Indiana 47405, USA

1. Lawrence, S. \& Giles, C. L. Nature 400, 107-109 (1999).

2. Encyclopedia Britannica, Inc. www.britannica.com (4 October 1999).

3. SciCentral. www.scicentral.com/index.html (4 October 1999).

4. Science NetLinks. www.sciencenetlinks.com/science/index. shtml (4 October 1999).

5. Fainzilber, M. Nature 401, 111 (1999).

\section{Where nuclear weapons come before basic needs}

Sir - In his review of the books by Itty Abraham and Michael Foot, Brahma Chellaney chastises Abraham for "his commitment to one side" of the nuclear debate in India which supposedly "weakens his arguments" (Nature 401, 113-114; 1999). Although Abraham's sympathies may well lie on the side of India's growing anti-nuclear movement, Chellaney is very much on the other side.

Chellaney is a member of India's National Security Advisory Board and an author of the draft "nuclear doctrine", which calls for "sufficient nuclear weapons to inflict destruction and punishment" ${ }^{\text {.1 }}$. So it comes as no surprise that he puts a positive gloss on the history of India's nuclear weapons, and paints an inaccurate picture of Abraham's book.

Chellaney persists in describing India's 1974 nuclear test as a "peaceful explosion". Such semantic evasions no longer carry any weight, if they ever did. Even Raja

Ramanna, former chairman of India's Atomic Energy Commission and the leader of the team that conducted the test, described it as "a prototype weapon".

Chellaney also attempts to suggest that India is unique among nuclear weapons states in having straddled the "nuclear fence" for a quarter of a century while having a democratic debate on whether it should "go nuclear". A less self-serving description would be that India spent decades building a ladder to climb over this imaginary nuclear fence and, when it came time to decide whether to jump down to the other side, a handful of people made the decision, as has always been the case in Indian nuclear policy ${ }^{3}$.

Abraham's book shows how Indian scientists used the ideologies of national security and national development to transform a small scientific laboratory into a full-blown weapons complex. His work demonstrates how the combination of science, ideology and the power of the state can be a recipe for disaster as much in the Third World as in the first and second.

Abraham's real achievement is to reveal the thinking of India's élite, which places nuclear weapons above providing even the most basic necessities to a large proportion of the country's citizens.

It is at this level, the right of ordinary people to make meaningful choices about their lives in an informed and democratic way, that Abraham is taking sides. It is a side he shares with Foot, but one far removed from the cabals of "the wizards of Armageddon" who make nuclear-weapons policy around the world.

\section{Zia Mian, M. V. Ramana}

Center for Energy and Environmental Studies, Princeton University, Princeton,

New Jersey 08544, USA

\footnotetext{
1. National Security Advisory Board Draft Report on Indian Nuclear Doctrine http://www.indianembassy.org/policy/CTBT/ nuclear_doctrine_aug_17_1999.html

2. Ramanna, R. Years of Pilgrimage 100 (Viking, New Delhi, 1991).

3. Ramana, M. V. Precis IX, No. 3, pp. 1 \& 21-25 (1998).
} 